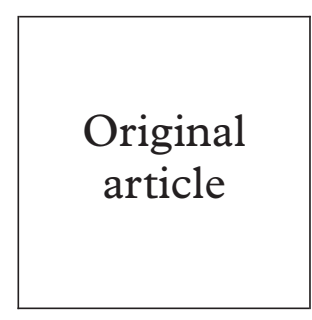

\title{
Low diagnostic accuracy of selective screening criteria for asymptomatic Chlamydia trachomatis infections in the general population
}

\author{
Irene G M van Valkengoed, Servaas A Morré, Adriaan J C van den Brule,
} Chris J L M Meijer, Walter Devillé, Lex M Bouter, A Joan P Boeke

Objectives: To develop and validate selective screening criteria for asymptomatic Chlamydia tra-
chomatis infections in the general population. Methods: 11505 people, aged 15-40 years, registered in 16 general practices in Amsterdam were invited to return by mail a home obtained first void urine sample and a questionnaire. Participants were randomly allocated into a development group $(75 \%)$ or a validation group $(25 \%)$. $C$ trachomatis infection was determined by the ligase chain reaction. In the development group a set of criteria was identified by means of stepwise logistic regression analysis. The diagnostic accuracy (area under the ROC curve; AUC) and sensitivity, and the corresponding percentage of people selected for screening were calculated. The criteria developed in this study were applied to the validation group.

Results: The prevalence of asymptomatic $C$ trachomatis infections among men was found to be $2.4 \%$ (1.7-3.0), and among women $2.8 \%$ (2.2-3.4). Screening men, based on Surinam/Antillean origin and painful micturition, yielded an AUC of 0.58 (0.55-0.60). Screening women, based on Surinam/Antillean origin, new sex partner in the previous 2 months, and unmarried/not cohabiting, yielded an AUC of 0.67 (0.65-0.69). Application of the criteria for men to the validation group yielded an AUC of 0.53 (0.48-0.57); by screening $10 \%$ of the men, $15 \%$ of the cases were detected. The AUC of the criteria for women in the validation group was 0.58 (0.54-0.61); by screening $51 \%$ of the women, $63 \%$ of the cases were detected.

Conclusion: The prevalence of asymptomatic $C$ trachomatis infections in Amsterdam is less than $3 \%$. No suitable selective screening criteria for the general population could be identified. (Sex Transm Inf 2000;76:375-380)

Keywords: screening; prevalence; Chlamydia trachomatis

\section{Introduction}

Genital infections caused Chlamydia trachomatis are the most prevalent sexually transmitted infections in the Netherlands, as well as in other industrialised countries. ${ }^{1}$ Since genital chlamydial infection causes no or few symptoms, many infections remain undetected. An untreated infection in women may lead to pelvic inflammatory disease (PID), and at a later stage to infertility, ectopic pregnancy, and chronic abdominal pain. ${ }^{2}$ Infected women can pass the infection on to their children at birth. ${ }^{3}$ Complications in men are less severe. Screening and treatment is indicated for men in order to prevent the infection from spreading.

Scholes et al have shown that screening for asymptomatic infections in women results in a reduction of $56 \%$ in the incidence of PID. ${ }^{4}$ In the past, most screening programmes have been opportunistic, focusing on patients attending healthcare clinics or specific high risk groups. The introduction of sensitive DNA detection methods to test non-invasively collected specimens, such as urine, ${ }^{5}{ }^{6}$ and the use of mailed home obtained samples makes it possible to extend screening beyond the traditional settings. $^{78}$

The efficiency of screening strongly depends on the prevalence of infections in the target population, and there is still a lack of estimates of the prevalence of asymptomatic infections in the general population. In inner city practices in London, a prevalence of $2.6 \%$ was found among sexually active women who were due for a routine health check up. Selective screening has been suggested as an efficient strategy, since universal screening may not be appropriate in a low prevalence population. ${ }^{9}$ Selective screening criteria for women have been suggested in various other studies. However, most of these criteria were derived from opportunistic or clinic based screening programmes, and may not be applicable in screening a general population. Furthermore, these criteria have seldom been evaluated in a population, other than that from which the criteria were derived, although the performance of these criteria in the development group is typically too optimistic. ${ }^{10-17}$ No selective screening criteria for men have yet been evaluated.

The objective of this study was to develop and validate selective screening criteria for a population based screening for asymptomatic $C$ trachomatis infections in an inner city population.

\section{Methods}

POPULATION

A random sample of 5791 men and 5714 women, aged 15-40 years, was selected from the computer registers of 16 inner city general practices in Amsterdam. All practices were 
selected based on previous research experience with the institute. The practices were spread throughout the city such that all districts of Amsterdam were represented in the study.

RECRUITMENT

Between March 1996 and November 1997 all patients who were selected for the sample received an invitation from their own general practitioner explaining the purpose of the study. Included with the letter was a card which could be returned if the patient was unwilling to participate. A urine container and a questionnaire were also sent to the home address of potential participants. To ensure anonymity, all materials were coded. Patients were requested to collect a first void, first stream urine sample and to complete the questionnaire. The questionnaire contained 29 (women) or 22 (men) open and closed questions on demographic variables, current urogenital symptoms, history of sexually transmitted diseases, and sexual behaviour. All information material and the demographic questions on the questionnaire were translated into the most relevant languages in Amsterdam-Dutch, English, Arabic, and Turkish. Patients were requested to return the urine samples and the questionnaire to the Department of Pathology in a prestamped addressed envelope, which was included in the material. Non-respondents were sent one single reminder 3 weeks after the material was mailed to them. At the end of the study, a nonparticipants study was also carried out. Every practice was requested to supply information on age, marital status, type of health insurance, and ethnic origin for 50 randomly chosen nonparticipants. Moreover, practitioners were requested to check whether the address listed in the computer register at the start of the study was correct.

The study has been approved by the medical ethics committee of the Vrije Universiteit in Amsterdam.

DETECTION OF C TRACHOMATIS

Urine samples were tested for the presence of $C$ trachomatis DNA by means of the ligase chain reaction (LCR) (Abbott Laboratories, Chicago, IL, USA) in the laboratory of the department of pathology of the University Hospital Vrije Universiteit. Tests were performed according to the instructions of the manufacturer, and the results of the tests were sent back to the practice in which the patient was registered. The general practitioners were instructed to treat infected patients with a single dose of $1000 \mathrm{mg}$ azithromycin, or erythromycin for pregnant women $(4 \times 500 \mathrm{mg}$ for 5 days), and to notify the partners.

\section{STATISTICAL ANALYSIS}

Development of the screening criteria

Participants were randomly allocated into a development group and a validation group (75\% and $25 \%$ of the participants, respectively). Participants who reported that they had never been sexually active were excluded from further analysis, since they were not at risk for the infection.

For the development group, univariate logistic regression analyses were performed, with self reported characteristics as independent variables and chlamydia diagnosis as the dependent variable. Variables showing an association of $\mathrm{p}<0.25$ for the Wald test were included in the multivariate analysis. If more than one variable measuring the same concept showed such an association, the variable which showed the strongest association was selected.

In the next stage, a forward stepwise logistic regression analysis was performed. Criteria for entry into the model and elimination from the model were a $\mathrm{p}$ value for the likelihood ratio test of 0.05 and 0.08 , respectively. In the resulting models, interaction terms were taken into consideration, but only those interaction terms that significantly improved the model were included. All logistic regression analyses were performed with the sPSS package version 7.5.2.

Subsequently, the probability of a $C$ trachomatis infection was calculated, using the formula:

$$
p(C \text { trachomatis })=\frac{1}{\varepsilon^{-\left(a+B_{l} \times x_{l}+\ldots B_{k} \times x_{k}\right)}}
$$

where $p$ (C trachomatis) is the probability of infection, $a$ is the constant, and $B$ represents the regression coefficient for every determinant interaction term $x$. Using the predicted probabilities, a receiver operator characteristic (ROC) curve, a plot of the sensitivity against 1 - specificity, was constructed in MEDCALC, version 4.20.021 (F Schoonjans, Belgium). The calculated area under the ROC curve (AUC) is a measure of the diagnostic accuracy: the chance of correctly classifying a randomly selected couple of positive/negative observations, irrespective of the cut off value for positivity. An AUC of less than 0.60 was considered to be poor, $0.60-0.75$ was moderate, and higher than 0.75 was good.

To ensure detection of a sufficient number of cases, a cut off point was chosen for each model, at which the calculated sensitivity was close to $80 \%$. The sensitivity, the percentage of the total population selected for screening (true positive fraction plus the false positive fraction), and the prevalence in the screened population (predictive value positive) were calculated at this cut off point.

A multilevel analysis was performed, using the MLWIN program version 1.02.0002, to account for variance at the level of general practice.

Validation of the model

The probability of infection for all patients in the validation group was calculated on the basis of the estimates of the coefficients for the model found in the development group. ${ }^{18}$ The AUC was calculated, and the sensitivity and the percentage of the population screened were determined at the same cut off value as chosen for the development group. 
Table 1 Characteristics of participants and non-participants in a screening programme for asymptomatic Chlamydia trachomatis infections by means of mailed, home obtained urine specimens

\begin{tabular}{|c|c|c|c|}
\hline \multirow[b]{2}{*}{ Characteristic } & \multicolumn{2}{|c|}{ Prevalence of characteristic (\%) } & \\
\hline & $\begin{array}{l}\text { Non-participants } \\
(n=548+)\end{array}$ & $\begin{array}{l}\text { Participants } \\
(n=3368)\end{array}$ & \\
\hline Age (years) & & & NS \\
\hline $15-20$ & 9.6 & 8.2 & \\
\hline $21-25$ & 13.6 & 16.2 & \\
\hline $26-30$ & 24.5 & 26.7 & \\
\hline $31-35$ & 30.2 & 26.8 & \\
\hline $36-40$ & 22.2 & 22.1 & \\
\hline Origin & & & $\mathrm{p}<0.001 \ddagger$ \\
\hline Dutch & 60.1 & 75.0 & \\
\hline Other European & 4.8 & 3.2 & \\
\hline Surinam/Antillean & 11.6 & 10.8 & \\
\hline Turkish/Moroccan & 13.8 & 5.4 & \\
\hline Other & 9.6 & 5.5 & \\
\hline Married or cohabiting & & & NS \\
\hline Yes & 45.5 & 48.3 & \\
\hline No & 54.5 & 51.7 & \\
\hline Type of health insurance & & & NS \\
\hline Government & 73.1 & 72.9 & \\
\hline Private & 26.9 & 27.1 & \\
\hline
\end{tabular}

$\star$ Participants from practices that supplied information on non-participants. †Information on two people was not supplied by practices. $\ddagger \chi^{2}$ test.

Table 2 Prevalence of asymptomatic Chlamydia trachomatis infections as detected by ligase chain reaction in urine, in men and women registered in inner city general practices in Amsterdam; total prevalence, prevalence according to age, and prevalence according to origin

\begin{tabular}{|c|c|c|c|c|}
\hline & \multicolumn{2}{|l|}{ Females } & \multicolumn{2}{|l|}{ Males } \\
\hline & Cases $/ n$ & $\begin{array}{l}\text { Prevalence (\%) } \\
{[95 \% \mathrm{CI}]}\end{array}$ & Cases $/ n$ & $\begin{array}{l}\text { Prevalence (\%) } \\
{[95 \% \mathrm{CI}]}\end{array}$ \\
\hline Total & $81 / 2902$ & $2.8[2.2-3.4]$ & $45 / 1908$ & $2.4[1.7-3.0]$ \\
\hline \multicolumn{5}{|l|}{ Age (years) } \\
\hline $15-20$ & $5 / 209$ & $2.4[0.3-4.5]$ & $1 / 149$ & $0.7[0-2.0]$ \\
\hline $21-25$ & $21 / 472$ & $4.4[2.6-6.3]$ & $8 / 246$ & $3.3[1.0-5.5]$ \\
\hline $26-30$ & $23 / 832$ & $2.8[1.6-3.9]$ & $15 / 476$ & $3.2[1.6-4.7]$ \\
\hline $31-35$ & $19 / 756$ & $2.5[1.4-3.6]$ & $14 / 575$ & $2.4[1.2-3.7]$ \\
\hline $36-40$ & $13 / 632$ & $2.1[0.9-3.1]$ & $7 / 462$ & $1.5[0.4-2.6]$ \\
\hline \multicolumn{5}{|l|}{ Origin } \\
\hline Dutch & $59 / 2204$ & $2.7[2.0-3.4]$ & $30 / 1368$ & $2.2[1.4-3.0]$ \\
\hline Other European & $3 / 104$ & $2.9[0-6.1]$ & $1 / 62$ & $1.6[0-4.8]$ \\
\hline Surinam/Antillean & $15 / 294$ & $5.1[2.6-7.6]$ & $9 / 162$ & $5.6[2.0-9.1]$ \\
\hline Turkish/Moroccan & $1 / 114$ & $0.9[0-2.6]$ & $3 / 148$ & $2.0[0-4.3]$ \\
\hline Other & $2 / 125$ & $1.6[0-3.8]$ & $2 / 122$ & $1.6[0-3.9]$ \\
\hline
\end{tabular}

$\mathrm{CI}=$ confidence interval.

Table 3 Determinants of infection with Chlamydia trachomatis for men and women in the development group (75\% of all participants) selected for the multivariate analysis ${ }^{\star}$

\begin{tabular}{|c|c|c|c|c|}
\hline \multirow[b]{2}{*}{ Sex } & \multirow[b]{2}{*}{ Determinant } & \multicolumn{2}{|c|}{ Prevalence determinant (\%) } & \multirow[b]{2}{*}{ OR $[95 \% C I]$} \\
\hline & & Cases & Non-cases & \\
\hline \multirow[t]{10}{*}{ Female } & Number & 62 & 2178 & \\
\hline & Age $\leqslant 25$ & 33.3 & 21.5 & $1.87[1.08-3.23]$ \\
\hline & Surinam or Antillean origin & 20.3 & 10.1 & $2.35[1.22-4.50]$ \\
\hline & Unmarried and not cohabiting & 71.2 & 47.6 & $2.79[1.58-4.95]$ \\
\hline & Heterosexual $\dagger$ & 98.3 & 93.9 & $3.92[0.54-28.51]$ \\
\hline & Sexual debut $<18$ years & 90.0 & 54.8 & $0.67[0.40-1.12]$ \\
\hline & New sex partner & 21.7 & 8.5 & $3.12[1.67-5.89]$ \\
\hline & Lower abdominal pain & 11.9 & 18.2 & $0.59[0.27-1.33]$ \\
\hline & Coloured discharge & 20.3 & 14.3 & $1.55[0.81-2.96]$ \\
\hline & Heavy vaginal discharge & 35.0 & 21.7 & $1.99[1.16-3.41]$ \\
\hline \multirow[t]{11}{*}{ Male } & Number & 32 & 1438 & \\
\hline & Age $\leqslant 30$ & 54.8 & 43.6 & $1.58[0.78-3.25]$ \\
\hline & Surinam or Antillean origin & 54.8 & 9.3 & $2.97[1.25-7.06]$ \\
\hline & Government health insurance & 61.3 & 70.3 & $0.66[0.31-1.38]$ \\
\hline & $\geqslant 15$ years of education & 72.4 & 54.9 & $2.19[0.96-4.98]$ \\
\hline & Sexual debut $<18$ years & 66.7 & 52.3 & $1.85[0.86-3.98]$ \\
\hline & $>5$ lifetime sex partners & 71.4 & 57.8 & $1.85[0.81-4.24]$ \\
\hline & Previous $C$ trachomatis & & & \\
\hline & infection & 10.3 & 4.9 & $2.31[0.68-7.85]$ \\
\hline & Urethral discharge & 6.5 & 1.9 & $3.69[0.83-16.39]$ \\
\hline & Painful micturition & 6.5 & 2.6 & $2.73[0.62-11.96]$ \\
\hline
\end{tabular}

^Only determinants selected for the multivariate analysis, based on a Wald test for univariate association of $\mathrm{p}<0.25$, are shown.

tWas not included in the final analysis, because there was only one homo/bisexual women with a $C$ trachomatis infection.

$\mathrm{OR}=$ odds ratio, $\mathrm{CI}=$ confidence interval.

\section{Results}

PARTICIPATION AND PREVALENCE

The overall participation rate among women was $51 \%$, and among men $33 \%$; 104 samples and questionnaires were excluded from analysis because the respondent was not selected for the study sample, four other patients were excluded because they provided insufficient urine.

Of the non-participants, $9 \%$ indicated on the postcard enclosed in the invitation that they were unwilling to participate. The questionnaire concerning non-participants was completed by 12 of the 16 practices. Other practices were unwilling to supply additional information about men and women who had (indirectly) declined to participate in the study, by not returning the questionnaire or sample.

After the study commenced, it was found that $18 \%$ of the non-participants no longer lived at the address listed in the computer register at the start of the study. Participants were more frequently of Dutch origin than nonparticipants (table 1). Age, marital status, and type of health insurance were similar in both groups.

The overall prevalence of asymptomatic $C$ trachomatis infections in women was $2.8 \%$ (2.2-3.4). The highest infection rates were found in women who were 21-25 years of age and in women who were of Surinam or Antillean origin. Among men the prevalence was $2.4 \%(1.7-3.0)$. The highest infection rates were found in men who were 21-30 years of age and among men who were of Surinam or Antillean origin (table 2).

In all, 125 women and 121 men reported that they had never had sexual contact, and were excluded from the analysis of selective screening criteria. Of these patients $65 \%$ were under 25 years of age.

\section{DEVELOPMENT OF THE SCREENING CRITERIA} (DEVELOPMENT GROUP)

Determinants associated with chlamydial infection in men and women according to univariate analysis $(\mathrm{p}<0.25)$ are shown in table 3. Determinants showing the strongest association with infections among sexually active women were Surinam or Antillean origin, age $\leqslant 25$ years, unmarried and not cohabiting, heavy vaginal discharge, and a new sex partner in the previous 2 months. Years of education, type of health insurance, lifetime number of sex partners, inconsistent condom use, vaginal douching, intermenstrual bleeding, blood loss after sexual intercourse, foul smelling discharge, painful or frequent micturition, and history of sexually transmitted infections showed no association at a level of $\mathrm{p}<0.25$ (data not shown).

Factors most strongly associated with the presence of an infection in sexually active men were Surinam or Antillean origin, more than 15 years of education and urethral discharge. Unmarried and not cohabiting, type of health insurance, frequent micturition, heterosexuality, and inconsistent condom use showed no association at a level of $\mathrm{p}<0.25$ (data not shown). 
Table 4 Determinants found to be associated with Chlamydia trachomatis infections in men and women in the development group (75\% of all participants) by stepwise logistic regressions analysis

\begin{tabular}{lllllll}
\hline & Determinants included in the model & OR & AUC [95\% CI] & $\begin{array}{l}\text { Sensitivity } \\
\text { (\%) }\end{array}$ & $\begin{array}{l}\text { \% of total } \\
\text { population } \\
\text { screened }\end{array}$ & $\begin{array}{l}\text { Prevalence in } \\
\text { screened } \\
\text { population (\%) }\end{array}$ \\
\hline Female model & Surinam or Antillean origin & 2.10 & $0.67[0.65-0.69]$ & $78^{\star}$ & 52 & 4.4 \\
& Unmarried and not cohabiting & 2.26 & & & \\
Male model & New sex partner previous 2 months & 2.44 & & & \\
& Surinam or Antillean origin & 3.01 & $0.58[0.55-0.60]$ & $26 \dagger$ & 12 & 5.4 \\
& Painful micturition & 3.04 & & & & \\
\hline
\end{tabular}

* The cut off value for men is a predicted probability $>1 \%$.

$\dagger$ The cut off value for women is a predicted probability $>2 \%$.

"\% of total population screened" is the true positive fraction + the false positive fraction, "prevalence in screened population" is the predictive value positive, $\mathrm{OR}=$ odds ratio, $\mathrm{CI}=$ confidence interval, $\mathrm{AUC}=$ area under the curve, a measure of diagnostic accuracy.

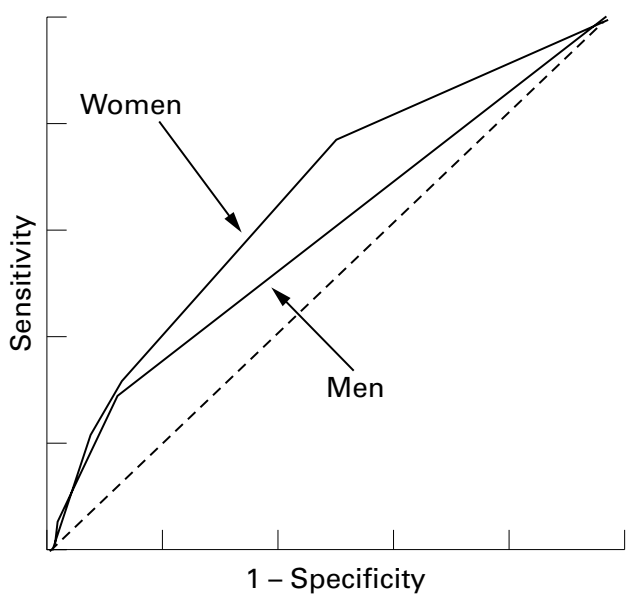

Figure 1 Receiver operator characteristic curves of selective screening criteria for men and women in the development group (75\% of participants). Female model: Surinam of Antillean origin, unmarried and not cohabiting. New sex partner in previous 2 months (AUC=0.67). Male model: Surinam or Antillean background, painful micturition $(A U C=0.58) . A U C=$ area under the curve.

Results of the multivariate analyses are presented in table 4 . The model for women was based on Surinam or Antillean origin, a new sex partner in the previous 2 months, and unmarried and not cohabiting. The model for men was based on Surinam or Antillean origin and painful micturition. No significant interactions were found for either model. ROC curves for both models are shown in figure 1 .

No effect of inclusion of the level of general practice was observed in the multilevel analysis (data not shown). Therefore, no further random effects models were considered.

VALIDATION OF THE SCREENING CRITERIA (VALIDATION GROUP)

Application of the criteria for women yielded an AUC of 0.58 (0.54-0.61); by screening 335 of the 662 women $(51 \%), 12$ of the 19 cases $(63 \%)$ were detected. The prevalence among screened women was $3.6 \%$. The AUC of the selective criteria for men in the validation group was $0.53(0.48-0.57)$; by screening $10 \%$ of the men (45/438), $15 \%$ of the cases $(2 / 13)$ were detected. The prevalence among screened men was $4.4 \%$.

\section{Discussion}

PARTICIPATION AND PREVALENCE

The prevalence of asymptomatic chlamydia infections among men and women in Amsterdam was less than $3 \%$. For women the rate is consistent with the prevalence found in a study among sexually active women in inner city London. ${ }^{9}$ Several opportunistic screening programmes have found higher prevalences. ${ }^{11-13}$ However, screening people who attend an STD clinic, a family planning clinic or other primary care clinic, probably overestimates the prevalence in the population as a whole. The highest prevalences in this study were found among men and women aged $21-25$ years, the lowest prevalences among people aged 15-20 years. The prevalences found in the latter age category are similar to prevalences found in a study among high school children in Antwerp. ${ }^{19}$ Other studies have found that highest prevalences occur among people aged 15-19 years. However, these studies were mostly opportunistic screening programmes targeted specifically at sexually active people. In our study we found that $40 \%$ of men and women aged 15-20 years had never been sexually active. These people should not be excluded when calculating the prevalence in the general population.

The participation rates found in the present study were of $33 \%$ for men and $51 \%$ for women. Similar rates have been reported in another study based on mailed home obtained samples. ${ }^{20}$ Strictly speaking participation rates are higher since at least $18 \%$ of the nonparticipants no longer lived at the registered address at the start of the study. The number of ghost patients could be as high as $32 \%$, the percentage of ghost patients reported in a recent study in Bristol. ${ }^{21}$ The participation rate in that study was $57 \%, 82 \%$ taking into account the ghost patients and nonresponders, after two postal contacts, a telephone call, and a home visit.

The use of telephone reminders and home visits could have potentially increased the participation rate in the current study. However, these were considered an unnecessary invasion of privacy by the medical ethics committee, since the programme was an unsolicited screening for healthy males and females. Direct (telephone) contact between researchers and participants was not allowed, except when requested by the participant. Participants were compared with non-participants on several demographic variables. Participants were found to be similar to non-participants with regard to marital status, type of health insurance, and age. However, participants were more likely than non-participants to be of Dutch origin. This may be due to cultural or 
language barriers, although information material for the study was provided in the four most relevant languages in Amsterdam. Participation rates were lowest among people with a Turkish/Moroccan origin, a group with a relatively low prevalence. There is no information available on other determinants of infection among non-participants, such as sexual risk behaviour.

The determination of the prevalence estimate could also have been affected by the quality of the test applied. Infections may have been missed because the sensitivity of the LCR on urine is less than $100 \% .{ }^{6}$ On the other hand, even though the specificity has been estimated to be approximately $99 \%$ in some studies, in a low prevalence population a considerable percentage of the positive test results could be false positives. In this study we used the LCR test on urine for both men and women. Other tests for $C$ trachomatis detection are available, such as TMA and PCR Cobas. It is not clear how the choice of the method would have influenced the results, since evaluation studies do not clearly demonstrate which test is superior. ${ }^{22}{ }^{23}$ For women other samples besides urine (for example, vaginal flush and vaginal swabs) have also been evaluated. ${ }^{724}$ These specimens have been shown to be more sensitive than urine for $C$ trachomatis detection. In future programmes these should be considered as a suitable alternative for urine.

\section{SELECTIVE SCREENING CRITERIA}

In contrast with studies carried out in other settings, age was found to be a poor predictor of infection in this study, even though people who had never been sexually active were excluded in the evaluation of screening criteria. The selective screening strategy for women in this study was based on Surinam or Antillean origin, unmarried and not cohabiting, and a new sex partner in the previous 2 months. However, the diagnostic accuracy of the criteria was, at best, moderate. Furthermore, application of the criteria to the validation group showed even poorer diagnostic accuracy, suggesting that in practice selection based on simple criteria is not adequate to distinguish clearly between infected and non-infected women in the general population.

This is thought to be the first study to evaluate selective criteria for men. In this study, screening men who were of Surinam or Antillean origin and reported painful micturition, identified a subgroup with a prevalence of $5.4 \%$. The criteria, however, would not be suitable for selective screening, since $75 \%$ or more of all cases in the population would remain undetected.

The results suggest that an effective selective screening strategy for a low risk population of men is difficult to achieve, if not impossible.

In this study symptoms such as lower abdominal pain for women and painful micturition for men were included in the development of screening criteria for asymptomatic $C$ trachomatis infections. People who list these complaints are, strictly speaking, not asymptomatic. However, a large portion of the popula- tion report least one symptom, even though they do not recognise the symptom as a sign of infection, do not consult a physician, and do not believe themselves to be at risk of an infection (unpublished data). We believe that these people should be included, since these infections would otherwise go undetected.

In conclusion, the prevalence of asymptomatic $C$ trachomatis infections in Amsterdam, as detected in urine specimens was found to be less than 3\%. Given the importance of early treatment to prevent complications, selective screening has been suggested by others as an efficient strategy for screening in low prevalence populations. ${ }^{9}$ In this study, no suitable selective screening criteria for men and women in general practice could be identified. However, if screening of the general population through general practice were initiated, a universal approach would seem more appropriate.

The authors would like to thank all practices and patients for taking the time to participate in the screening. Moreover, they taking the time to participate in the screening. Moreover, they
are grateful to Robert Moes and Katja Niessen for their are grateful to Robert Moes and Katja Niessen for their excellent technical assistance with the $C$ trachomatis assays.
Many thanks also to Inge van der Leden for her contribution in Many thanks also to Inge van der Leden for her contribution in coordinating the screening programme and the data manage-
ment. Finally, the authors would like to thank Drs J Twisk and ment. Finally, the authors would like to thank Drs J Twisk and
$H$ Adèr for their expert advice on the multilevel analysis of the data.

This study was supported by the Zorg Onderzoek Nederland (previously called the Prevention Fund) grants 28-2588 and 28-1182-1.

Conflict of interest: none

Contributors: IGMvV was responsible for the participant recruitment and epidemiological/statistical data analysis, study design, study coordination, database management, participated in the coordination of contact with the general practitioners, and in the coordination of contact with the general practitioners, and wrote the paper; SAM was responsible for the Chlamydia trachomatis detection, laboratory aspects, and participated in writing the paper; CJLMM initiated, designed and coordinated the study, obtained approval from the ethics committee, and participated in writing the paper; $\mathrm{AJCvdB}$ was involved in the laboratory aspects, study logistics and data interpretation. Initiated, designed and coordinated the study, and participated in writing the paper; WLGMD participated in the eppidemiological/statistical data analysis and participated in writing the paper; LMB coordinated the study and participated in writing the paper; AJPB was responsible for the participant recruitment and epidemiological/statistical analysis, initiated and designed the study, participated in the coordination of contact with the general practitioners, and participated in writing the paper.

1 Laar MJW van de, Ossewaarde JM, eds. Sexually transmitted diseases in the Netherlands; update 1996 [in Dutch]. Bilthoven: diseases in the Netherlands; update 1996 .

2 Wølner-Hanssen P, Kiviat NB Holmes KK. Atypical pelvic inflammatory disease: subacute, chronic, or subclinical upper genital tract infection in women. In: Holmes KK, Mårdh $\mathrm{P}-\mathrm{A}$, Sparling $\mathrm{PF}$, Wiesner $\mathrm{PJ}$, eds. Sexually transmitted diseases. 2nd ed. New York: McGraw-Hill Book, 1990:615-26.

3 Schachter J, Grossman M, Sweet RL, et al. Prospective study of perinatal transmission of Chlamydia trachomatis. $7 A M A$ 1986;255:3374-7.

4 Scholes D, Stergachis A, Heidrich FE, et al. Prevention of pelvic inflammatory disease by screening for cervical chlamydial infection. N Engl f Med 1996;334:1362-6.

5 Doornum GJ van, Buimer M, Prins M, et al. Detection of Chlamydia trachomatis infection in urine samples from men and women by ligase chain reaction. 7 Clin Microbiol men and women

6 Mouton JW, Verkooyen R, Meijden WI van der, et al. Detection of Chlamydia trachomatis in male and female urine specimens by using the amplified Chlamydia trachomatis test. F Clin Microbiol 1997;35:1369-72.

7 Østergaard L, Møller JK, Andersen B, et al. Diagnosis of urogenital Chlamydia trachomatis infection in women based on mailed samples obtained at home:multipractice comparative study. BMF 1996;313:1186-9.

8 Morré SA, Valkengoed IGM van, Jong A de, et al. Mailed, home-obtained urine specimens:a reliable screening approach for detecting asymptomatic Chlamydia trachomatis infections. F Clin Microbiol 1999;37:976-80.

9 Grun L, Tassano-Smith J, Carder C, et al. Comparison of two methods of screening for genital chlamydial infection in women attending in general practice:cross sectional survey. $B M \mathcal{F}$ 1997;315:226-30.

10 Gaydos CA, Howell MR, Pare B, et al. Chlamydia trachomatis infections in female military recruits. $N$ Engl $\mathcal{F}$ Med 1998;339:739-44. 
11 Oakeshott P, Hay P. General practice update:chlamydia infection in women. Br f Gen Pract 1995;45:615-20.

12 Stergachis A, Scholes D, Heidrich FE, et al. Selective screening for Chlamydia trachomatis infection in a primary care population of women. Am F Epidemiol 1993;138:14353.

13 Marrazzo JM, Celum CL, Hillis SD, et al. Performance and cost-effectiveness of selective screening criteria for Chlamydia trachomatis infection in women. Implications for a national chlamydia control strategy. Sex Transm Dis 1997;24:131-41.

14 Alary M, Joly JR, Moutquin JM, et al. Strategy for screening pregnant women for chlamydial infection in a lowprevalence area. Obstet Gynecol 1993;82:399-404

15 Humphreys JT, Henneberry JF, Rickard RS, et al. Cost-benefit analysis of selective screening criteria for Chlamydia trachomatis infection in women attending Colorado family planning clinics. Sex Transm Dis 1992;19: 47-530.

16 Finelli L, Nakashima AK, Hillis S, et al. Selective screening versus presumptive treatment criteria for identification of women with chlamydial infection in public clinics: New Jersey. Am 7 Obstet Gynecol 1996;174:1527-33.

17 Howell MR, Quinn TC, Gaydos CA. Screening for Chlamydia trachomatis in asymptomatic women attending family planning clinics. A cost-effectiveness analysis of three strategies. Ann Intern Med 1998;128:277-84.
18 Hosmer DW, Lemeshow S. Applied logistic regression. New York: Wiley, 1989.

19 Vuylsteke B, Vandenbruaene M, Vandenbalcke P, et al. Chlamydia trachomatis prevalence and sexual behaviour among female adolescents in Belgium. Sex Transm Inf $1999 ; 75: 152-5$

20 Østergaard L, Andersen B, Olesen F, et al. Efficacy of home sampling for screening of Chlamydia trachomatis: randomised study. $B M 7$ 1998;317:26-7.

21 Macleod J, Rowsell R, Horner P, et al. Postal urine specimens:are they a feasible method for genital chlamydial specimens:are they a feasible method for genital chlam
infection screening? Br f Gen Pract 1999;49:455-8.

22 Morre SA, Van Valkengoed IGM, Moes RM, et al. Determination of Chlamydia trachomatis prevalence in an asymptomatic screening population: performances of the $\mathrm{LCx}$ and Cobas Amplicor tests with urine specimens. F Clin Microbiol 1999;37:3092-6.

23 Puolakkainen M, Hiltunen-Back E, Reunala T, et al. Comparison of performances of two commercially available tests, a PCR assay and a ligase chain reaction test, in detection of urogenital Chlamydia trachomatis infection. $\mathcal{f}$ Clin Microbiol 1998;36:1489-93.

24 Stary A, Najim B, Lee HH. Vulval swabs as alternative specimens for ligase chain reaction detection of genital chlamydial infection in women. $\mathcal{F}$ Clin Microbiol 1997;35: 836-8. 